\title{
AYKUT, S., FOYER, J. Y MORENA, E. (EDS.) (2017) GLOBALISING THE CLIMATE: COP21 AND THE CLIMATIZATION OF GLOBAL DEBATES. NUEVA YORK: EARTHSCAN Y ROUTLEDGE.
}

La XXI Conferencia de Partes de la Convención Mundial del Cambio Climático (COP21), celebrada en París en 2015, fue una cumbre global de gran importancia. Vista por muchos como la encrucijada histórica para alcanzar acuerdos duraderos sobre la catástrofe climatológica mundial, la COP21 reunió a negociadores, científicos, periodistas, empresarios y representantes de la sociedad civil y se constituyó como una vitrina incomparable para estudiar el funcionamiento de la gobernanza ambiental global, en tiempo real. Globalising the climate: COP21 and the climatisation of global debates ofrece a sus lectores un análisis del desenvolvimiento de esta conferencia y su impacto en la gobernanza climática.

El libro ofrece los hallazgos obtenidos por un equipo multidisciplinario de veinte académicos expertos en gobernanza ambiental sobre la COP21. Haciendo uso de una etnografía de evento sobre las múltiples actividades de la conferencia (desde las mesas de negociación y los discursos oficiales hasta mítines, exposiciones artísticas y conferencias públicas de actores de la sociedad civil), Globalising the climate estudia las transformaciones actuales en la política del cambio climático, así como el impacto del cambio climático sobre otros debates políticos, económicos y sociales a escala global.

La riqueza académica de este libro proviene de su abordaje particular. En lugar de solamente concentrarse en estudiar los resultados formales que surgen de estos "mega-eventos globales" (e.g.: los acuerdos y declaraciones oficiales), el equipo de investigación abordó las múltiples prácticas performativas que los diferentes actores participantes usaron para incidir sobre la construcción de estos resultados. Así, hay contribuciones que exploran el proceso delicado - pero sumamente político - de construcción de lenguaje que acompaña la redacción de los acuerdos oficiales. Otras analizan cómo la ciencia del cambio climático - usualmente presentada como políticamente neutral - se construye de una manera que permite definir metas políticas. Varios otros capítulos estudian la manera en que se han formado economías políticas de ideas alrededor de la participación (y el dinero) de otros actores clave, como empresarios, filántropos y cooperantes.

$\mathrm{El}$ argumento amalgamador del libro es que la COP21 y sus predecesoras, lejos de "resolver" el cambio climático, buscaban "hacerlo gobernable". Es decir, la intención de estas conferencias es encontrar formas de definir y redefinir el cambio climático de una forma que pueda ser incorporado dentro de los órdenes geopolíticos y culturales actuales y hacerlo susceptible a las rutinas institucionales y organizacionales ya existentes. Puesto de otro modo, el objetivo es "construir el cambio climático" para (re-)constituir y (re-)consolidar la hegemonía global y la legitimidad política de las instituciones que han sido creadas para abordarlo. En estos términos, la intención es la formación de un régimen climático global, entendido como el andamiaje político que busca 
regular la interacción entre seres humanos y naturaleza, bajo los términos de un entendimiento capitalista del cambio climático.

En su introducción, los editores Foyer, Aykut y Morena describen la constitución del régimen climático como un proceso dual compuesto de la 'globalización del problema climático' y la 'climatización del mundo' El primer lado de este proceso tiene que ver con cómo las COP amplían la jurisdicción del régimen climático, incluyendo dentro suyo nuevos asuntos y actores. La otra cara de la moneda es la 'climatización del mundo' entendida como el proceso mediante el cual estos asuntos son redefinidos exclusivamente desde las lógicas dominantes en que se discute el cambio climático. Un ejemplo particularmente relevante de este proceso se expone en el capítulo de Jean Foyer y David Dumoulin que discute cómo las COP han servido para estandarizar y "hacer legibles" algunos principios sobre los conocimientos indígenas tradicionales, pero a costas de remover las implicaciones más radicales del reconocimiento de estos derechos. Otro ejemplo igualmente importante es la manera en que la atención del cambio climática privilegia "soluciones" de mercado, obscureciendo las desigualdades socioambientales que genera. Viard-Crétat y Buffet, en este volumen, explican esto señalando cómo que acciones para la promoción de plantaciones forestales, facilitan la producción de biomasa que mitiga el cambio climático, a costas de la pérdida de biodiversidad, el desgaste de recursos hídricos y los desplazamientos forzados de poblaciones locales.

COP21 fue crucial para este proceso dual. Entendida en el libro como una "máquina climatizante", la Conferencia de París amplio la jurisdicción del régimen climático sobre una gran cantidad de nuevos temas (e.g.: seguridad, agricultura, regulación financiera, etc.). Pero también, la COP21 es el momento culminante de la transición de una gobernanza basada en comando y control (e.g.: metas obligatorias de reducción de emisiones a escala nacional bajo supervisión de los estados) a una acción climática voluntaria y desde el mercado (e.g.: iniciativas corporativas y empresa privada). En los párrafos siguientes enmarco las diferentes contribuciones del libro en torno a este cambio fundamental.

Los capítulos escritos por Stefan Aykut y Monica Castro estudian cómo se incluyen o no temas y tópicos en las instituciones formales del cambio climático. En el caso de Aykut, se ofrece una revisión sumamente detallada de las prácticas performativas que toman lugar a la hora de diseñar el texto jurídico de los acuerdos climáticos, determinando las dimensiones cognitivas para entender qué es el cambio climático y cómo debe abordarse políticamente. Aykut y Castro, en otro capítulo, analizan estas dinámicas relativo a la paradoja de la no inclusión del tema de generación de energía dentro de las negociaciones, a pesar de ser uno de los orígenes mejor reconocidos del cambio climático. En gran medida, la idea que une estos trabajos es conocer cómo es que el cambio climático es convertido en una institución política global.

Los demás trabajos del libro describen las dimensiones más estratégicas de la climatización, valorando las prácticas y discursos de diferentes actores políticos en la COP21, en perspectiva histórica. Benabou, Moussu y Müller exploran cómo 
la empresa privada proyectó una voz unificada y, en apariencia, "progresiva", en el marco de la COP21. El artículo describe la manera en que estos grupos anticiparon críticas de otros actores, moldeándose como un actor proactivo, que, por lo tanto, no requiere ser objeto de regulación. Combry, Morena y de Joost analizan el dilema de los movimientos sociales sobre cómo situarse relativo a la conferencia, ya sea como actores "dentro" de la COP o activismo "desde fuera". Por otro lado, Guillemot describe la forma en que la meta actual de evitar aumentos en la temperatura global arriba de $1,5^{\circ} \mathrm{C}$ surge no como una necesidad científica, sino que una declaración política. Reflexionando sobre el origen de esta meta, se explica la difícil adaptación de las comunidades científicas en torno a las agendas y demandas de la "política" del cambio climático.

Morena, en otro capítulo, también ofrece un análisis bastante completo de la climatización refiriéndose a cómo filántropos liberales han jugado un rol clave pero discreto - en la formulación final de los acuerdos de la conferencia. $\mathrm{Su}$ capítulo ofrece un vistazo al rol histórico que la filantropía ha jugado en la organización del régimen climático global, determinando su abordaje basado en enfoques reformistas dentro de la economía neoliberal y evitando acciones más radicales. Finalmente, enfocándose en dos mecanismos creados y moldeados por las COP - la estrategia REDD+ para evitar emisiones de dióxido de carbono producto de deforestación y degradación forestal - Viard-Crétat y Buffet demuestran cómo el cambio climático también ha sido usado para ponerle un nuevo nombre a viejas y vetustas prácticas de cooperación para el desarrollo.

Globalising the climate constituye un volumen bastante meritorio y de gran utilidad, tanto para expertos como para su uso como material didáctico en las aulas, aunque debe decirse que algunos capítulos quizás resulten ser difíciles de leer producto del complejo lenguaje técnico que acompaña la gobernanza sobre cambio climático. En general, se ofrecen contribuciones que son bienvenidas en un momento en que el estudio crítico del cambio climático se encuentra fuertemente criticado por su débil abordaje de la multivocalidad en la construcción de resultados. En efecto, el libro aborda efectivamente algunas de las limitaciones de este enfoque: (1) presentando la riqueza de las relaciones entre actores de forma compleja e intricada, y (2) trascendiendo un enfoque monolítico que termina reduciendo a ciertos actores como buenos o malos.

Al contrario, se ofrece un caleidoscopio de perspectivas que informan el proceso de negociación sobre el cambio climático. En general, encuentro que Globalising the climate es un libro de enorme utilidad para lectores que buscan profundizar su conocimiento de la forma en que se estudia, discute, define y gobierna el cambio climático, y aunque ya tiene tiempo desde que fue publicado (2017), sus conclusiones siguen siendo importantes para el estudio de la gobernanza climática hoy.

Alonso Ramírez Cover

alonso.ramirezcover@ucr.ac.cr

Costarricense, Doctor en Estudios del Desarrollo. Profesor de la Escuela de Ciencias Políticas, Universidad de Costa Rica. 